\title{
Dissecting our advances
}

\author{
Michael J. Reardon, MD, and Alan B. Lumsden, MD
}

From the Department of Cardiovascular Surgery, Houston Methodist Hospital, Houston, Tex.

Disclosures: Authors have nothing to disclose with regard to commercial support.

Received for publication Jan 12, 2017; accepted for publication Jan 26, 2017; available ahead of print Feb 21, 2017.

Address for reprints: Michael J. Reardon, MD, Department of Cardiovascular Surgery, Houston Methodist Hospital, 6550 Fannin, Suite 1401, Houston, TX 77030 (E-mail: mreardon@ houstonmethodist.org).

J Thorac Cardiovasc Surg 2017;153:S80-1

$0022-5223 / \$ 36.00$

Copyright $(2017$ by The American Association for Thoracic Surgery

http://dx.doi.org/10.1016/j.jtcvs.2017.01.015

Students of the thoracic aorta always have had a strong interest in ascending aortic dissection. The story of King George dying of an acute ascending aortic dissection with tamponade while straining on the toilet in 1760 is well known. Rene Laennec gave us the somewhat-misleading term, dissecting aneurysm, in 1819. Ascending aortic dissection remained a disease beyond surgical repair until the first successful case in Houston by DeBakey and Cooley in 1954. ${ }^{1}$ Ironically, Dr DeBakey developed an acute ascending aortic dissection at age 97 years and underwent a successful repair at the Houston Methodist Hospital. He recovered and returned to work until just shy of his 100th birthday.

Many pioneering surgeons have accumulated substantial work since this first repair. From our perspective, a major advance in our understanding and treatment of aortic dissection was the creation of the International Registry of Aortic Dissection (IRAD) to collect these advances. Type A aortic dissection remains the most common cause of death in acute aortic syndromes. Surgery for type A repair is a prime example of life-saving surgery but remains a procedure with appreciable mortality and morbidity. The article by Parikh and colleagues ${ }^{2}$ in this issue of the Journal looks at changes in the operative approach to type A dissection for patients in the IRAD interventional cohort. A systematic look at changes in operative strategy is timely as we examine the improvements in care.

This paper looks at 1732 patients with type A dissection treated between 1996 and 2016 in the IRAD interventional cohort divided into 3 time tertiles. These time periods vary in length but were chosen to allow a more even distribution of patients. Consistent across these time periods was the use of open distal anastomosis that we agree is imperative. Decreasing with time has been use of the femoral artery for inflow and increasing with time was the use of axillary artery cannulation. Right axillary cannulation is the current in flow of choice in our program and used in more than $90 \%$ of cases.

With time, techniques that spare the aortic valve have increased as well as the use of biologic valves when aortic

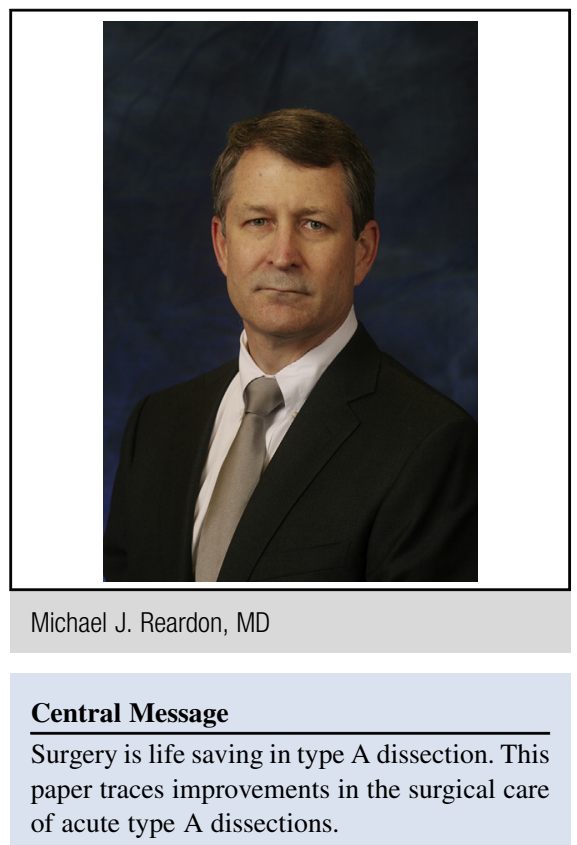

See Article page S74.

valve replacement is needed. The use of hemiarch replacement has increased along with the use of hypothermia with antegrade perfusion rather than hypothermia alone. The end result is an in-hospital mortality which has decreased from $17.5 \%$ to $12.2 \%$ over these time periods. Predictive of increased mortality were age older than 70 years, renal failure, and concomitant coronary artery bypass grafting procedure. Predictors of decreased mortality were hemiarch procedure and antegrade cerebral perfusion.

Although mortality has decreased sequentially with time, the authors do not provide information as to the cause of death. Specifically, although the cerebral perfusion strategy changed, was this reflected in a reduced incidence of stroke? Cerebral protection is an increasingly hot topic in transcatheter aortic valve replacement and branch aortic endografting. We believe that new cerebral monitoring strategies will need to be developed. There have been clearly dramatic technical improvements in type A dissection repair. Continued improvement likely will necessitate a greater focus on the cerebral circulation rather than just the aorta itself. Lessons learned in type A dissection may yield understanding that impacts many of the more complex interventions being developed. 
We congratulate the authors for this helpful study and would encourage a future study on procedural adjuncts to facilitate future downstream thoracic endovascular aortic repair when needed. In addition, there are now early feasibility studies being done for the use of stent grafts to treat these dissections, a source for future IRAD studies.

\section{Reference}

1. DeBakey ME, Cooley DA, Creech O Jr. Surgical considerations of dissecting aneurysm of the aorta. Ann Surg. 1955;142:586-612.

2. Parikh N, Trimarchi S, Gleason TG, Kamman AV, di Eusanio M, Myrmel T. Changes in operative strategy for patients enrolled in the International Registry of Acute Aortic Dissection interventional cohort program. J Thorac Cardiovasc Surg. 2017;153:S74-9. 